\title{
A CARTOGRAFIA SOCIAL NO CONTEXTO ESCOLAR: ESTUDANDO ESPACOS VIVIDOS A PARTIR DAS REPRESENTAÇÕES DE PAISAGENS
}

\author{
Social cartography in the school context: \\ studying lived spaces from landscapes representation \\ Paulo Roberto Florêncio de Abreu e Silva * \\ Antonio Carlos Castrogiovanni ** \\ * Prof. Adjunto no Depto de Geografia da Universidade de Pernambuco (Mata Norte) \\ paulodeabreu2013@hotmail.com \\ ** Universidade Federal do Rio Grande do Sul (UFRGS) \\ castroge@ig.com.br
}

Recebido em 17/06/2020. Aceito para publicação em 18/02/2021.

Versão online publicada em 23/03/2021 (http://seer.ufrgs.br/paraonde)

Como citar este artigo: ABREU E SILVA, P. R. F de. CASTROGIOVANNI, A. C. A cartografia social no xontexto escolar: estudando espaços vividos a partir das representações de paisagens. Para Onde!?, v. 15, n. 1, p. 01-15, 2021.

\begin{abstract}
Resumo:
Este artigo trata dos diferentes movimentos cartográficos. É um recorte de uma pesquisa baseada na possibilidade dos sujeitos alunos do Ensino Fundamental em representar as paisagens do espaço vivido a partir da problematização da lógica cotidiana. O trabalho está ancorado na Teoria da Complexidade no qual é necessário uma constante autoria reflexiva. Desta forma, esta contribuição trilha para desafios de ensinar a Geografia numa dialógica com a Cartografia e a Cartografia Social. Apesar das constantes mutações, a paisagem é única, mas é processual. Consideramos a dinâmica relacional porque cada sujeito é envolvido na constituição de cada paisagem. A paisagem parece se revitalizar através das representações sociais que elaboramos sobre ela. Além disso, consideramos os fatores objetivos e subjetivos através da complexidade do olhar que reflete nos estudos geográficos. Mas como compreender a paisagem se é processual? Através do conhecimento e da dúvida que criam o poder que é exercido pelos sujeitos de maneira individual ou em grupo. É nesta conotação que este artigo objetiva considerar a Cartografia Social nas aprendizagens de Geografia. Ele é um recorte de uma pesquisa ancorada na Pesquisa Qualitativa de cunho bibliográfico e experimental. Portanto, sua metodologia é baseada nas experiências enquanto aproximação com uma constante pesquisaação. Isso ocorre a partir da importância que tem o conhecimento cartográfico construído nas escolas. Os alunos, considerados como sujeitos sociais, devem questionar, analisar, diagnosticar complexidades provisórias. Neste sentido, eles devem ser partícipes sociais no território de (com)vivência.
\end{abstract}

Palavras-chave: Cartografia Social. Cartografia. Ensino de Geografia. Complexidade.

\section{Abstract:}

This article deals with the different cartographic movements. It is an excerpt from a research based on the possibility of elementary school students to represent landscapes of the lived space from the problematization of everyday logic. The work is anchored in Complexity Theory in which constant reflexive authorship is necessary. 


\begin{abstract}
Thus, this contribution to the challenges of using Geography in a dialog with Cartography and Social Cartography. Despite the constant changes, the landscape is unique, but it is procedural. Consider the relational dynamics because each subject is basic in the constitution of each landscape. The landscape seems to be revitalized through the social representations that we elaborate about it. In addition, it considers objective and subjective factors through the complexity of the look that reflect geographic studies. But how to understand the landscape if it is procedural? Through knowledge and doubt that create the power that is exercised by the subjects individually or in a group. It is in this connotation that this article aims to consider Social Cartography in the learning of Geography. It is an excerpt from a research anchored in the Qualitative Research of bibliographic and experimental nature. Therefore, its methodology is based on experiences while constant action research is approaching. This occurs due to the importance of the cartographic knowledge built in schools. Students, considered as social subjects, must question, analyze, diagnose provisional complexities. In this sense, they must be social participants in the territory of (with) experience.
\end{abstract}

Keywords: Social Cartography. Cartography. Geography teaching. Complexity.

\title{
1. Introdução
}

$\mathrm{Na}$ contemporaneidade, o conceito de Cartografia Social, tem provocado estudos de diferentes áreas sobre a sua relevância na representação e compreensão da sociedade e as suas interações. Desta forma, Guareschi, (2010, p.78), pontuam que a Cartografia Social "Está especialmente interessada no fenômeno das representações sociais, que compreende os saberes produzidos na e pela vida cotidiana". Para nós as representações sociais são abstrações relacionadas ao modo particular de cada sujeito em compreender a realidade e de se comunicar construindo expressões que possam gerar conhecimentos autorais, substantivados e consensuais sobre o espaço geográfico. Por produzir conhecimentos, implica em uma interpretação e em uma comunicação, que corrobora com o nosso objetivo, no sentido de trabalhar a Cartografia Social, no Ensino Fundamental, mesmo provisoriamente, com os fatos que podem causar estranhamentos silenciosos ou mesmo perturbadores, em algo coletivo e participativo.

Pensamos que as representações do cotidiano pelos sujeitos, com os seus aspectos naturais, através da dinâmica perspectiva e subjetiva, parece proporcionar, quando estimulados, novos olhares interpretativos sobre o espaço vivido, pois até então nesses olhares predomina o caráter empírico vivencial. Entendemos por olhar interpretativo aquele que leva o sujeito a problematizar e a fazer síntese sobre o que vê e que muitas vezes parece não enxergar. Com esta leitura, este trabalho preocupa-se em pesquisar práticas sugestivas para que o professor possa estimular os seus alunos a descobrir a paisagem com o olhar repleto de dúvidas, o que deve estimular a prática de pesquisa.

Nossas reflexões trilham nas possibilidades de trabalharmos a Cartografia Social nas aulas de Geografia, superando a dicotomia Geografia Física e Geografia Humana, proporcionando aos alunos serem autores e/ou co-autores da transformação do vivido, a partir da observação, em conhecimento provisório.

Nossa intensão é direcionar os estudos da Cartografia Social não aos agentes sociais especializados, mas aos alunos do Ensino Fundamental, que podem 
construir as suas representações oriundas das interações, em auxilio ao entendimento dos conhecimentos trazidos pela Cartografia Escolar e do estudo das paisagens. As autoras Sousa e Katuta (2001, p.77) pontuam que: "Leiturizar geográfica e cartograficamente o aluno, implica não somente ensiná-lo a ler o "alfabeto cartográfico", mas também ensiná-lo a construir pensamentos sobre a representação." Pensamos que o ensino da representação cartográfica no currículo escolar está atribuída à Geografia.

Um dos desafios é refletirmos: em uma turma de alunos, quantos diferentes olhares podem estabelecer representações distintas? Enxergam o mundo com lógicas particulares? Todos os olhares necessitam ser valorizados. A soma destes olhares é mais que uma única visão do todo complexo que pode se apresentar o Espaço Geográfico. Atenção, esta diversidade de olhares é uma riqueza. Os professores precisam considerá-la e pensar que contribuem para o conflito de ideias que devem ser valorizadas nas práticas inovadoras.

É relevante despertarmos para a leitura das paisagens através da percepção não apenas estética, mas gerando movimentos de estranhamento, proporcionando ações através de julgamentos, muitas vezes subjetivos, mas que são verdades provisórias É importante termos presente que o mundo que se mostra, pode não ser o mundo que devessemos olhar. Portanto, merece ser problematizado na ação pedagógica e, consideradas as suas diversas representações. Quando falamos em ler a paisagem estamos nos referindo a não apenas descrever o que vemos, mas buscar o que está escondido nos processos de interação entre os seus elementos ao longo do processo histórico. Toda paisagem se reordena através de movimentos, naturias ou provocados por ações sociais. O que vemos agora não é mais o que tinhamos visto antes e nem o que veremos a seguir.

Segundo Vieira e Verdum, (2017, p.130) "[...] se admiram as paisagens buscando essencialmente as sensações que elas nos fornecem pela sua beleza, pela sublimidade, pelo pitoresco. É uma busca pelas paisagens que são dignas de serem representadas em uma imagem". Desta forma, propomos estabelecer pontes entre os conhecimentos cartográficos e o conceito de paisagem, no sentido de levar os alunos a buscarem o olhar complexo, através dos cinco sentidos - visão, audição, olfato, tato e paladar, bem como representá-los, apontando problematizações, explicações e sínteses provisórias, despertando uma nova visão de mundo que está em constante (re)construção.

A paisagem pode ser entendida como resultado das marcas que a sociedade imprime na superfície terrestre ao longo do tempo e estão em constantes transformações ocasionadas por dinâmicas físicas, sociais, econômicas e culturais (VERDUM, VIEIRA, PIMENTAL, 2016). É na paisagem cotidiana que podemos iniciar a provocação aos alunos para descobrirem algo que ainda não viram. A investigação sobre esta paisagem que oculta alvos e que traz uma gênese, deve ser provocativa e instigante, fazendo os sujeitos perceberem que muitas vezes vemos, mas nem sempre abstraimos o mundo que auxiliamos construir.

Por conseguinte, trabalhar a Cartografia Social direcionada à visão holística das paisagens parece ser um caminho estimulante ao aprendizado de um sujeito atuante. Representar não apenas o visto, mas o que é sentido expressa uma leitura do Espaço geográfico. Este movimento contribui para romper processos lineares de 
ensinar e aprender, ainda tão presente em nossas escolas.

Portanto, através deste sentimento, cada sujeito envolvido na representação da paisagem será o autor da (nova) paisagem e terá como objetivo tornar o seu lugar visível e analisado, pois cada um de nós compõe a paisagem. Questionamos: será que para o aluno tornar-se um sujeito consciente, é necessário encontrar-se enquanto agente social, ou não? Entendemos que sim, pois, o olhar crítico cotidiano de tantas disputas sociais parece clarear a contemplação e enfatiza a importância da sua participação.

Enquanto professores, temos nos perguntado cotidianamente que olhar contempaltivo cada aluno traz? Acreditamos que na maioria das vezes ele não teve oportunidades de problematizar esta possibilidade. O cotidiano do ir e vir parece dificultar o enlevo. Daí ser necessária a construção das habilidades da observação, da leitura problematizada, descrição do espaço em que atuamos e que construímos o seu sentido constantemente.

Esta leitura problematizante do espaço, em nosso entender, inicialmente deve valorizar as suas formas, as suas funções, estruturas e processos, o que dificilmente damos conta em um primeiro olhar. Corrobora com este sentimento, Santos (1985), ao esclarecer que essas categorias de análise são indissociáveis entre si, e se interpenetram através da dialética, por isso não podemos considerar uma categoria isoladamente, pois se torna sem sentido.

É fundamental o professor de Geografia junto com os seus alunos se preocuparem com o trabalho de campo, pois pode ser um bom caminho na contemplação da paisagem com diferentes lógicas interpretativas, isto é, com o olhar de pesquisador. É como diz Panizza (2014, p. 43): "Só existe paisagem no espaço do olhar". Assim, trabalhar a problematização nos diferentes olhares dos diversos alunos passa a ser um caminho metodológico importante na leitura do espaço geográfico para o seu provisório entendimento.

Esse caminho se ancora nos procedimentos metodológicos das ações de mapeamento social que pode ter o seu amparo num movimento contínuo e não linear: ação-reflexão-considerações provisórias-novas ações. Neste trabalho, damos evidências às revisões teóricas, bem como à prática sugestiva para o Ensino Fundamental. Tem como objetivo considerar a Cartografia Social como auxilio para o entendimento dos conteúdos que competem à Geografia.

Entendemos que nesta dialógica no ensinar Cartografia Escolar e trabalhar com a Cartografia Social, um dos conceitos estruturantes da Geografia, é a Paisagem, por traduzir de forma materializada o espaço onde os alunos se constituem enquanto sujeitos.

\section{Os movimentos cartográficos no desenvolvimento da criticidade social}

A construção dos conteúdos da Cartografia Escolar, constituem meios de iniciação ao estudo das paisagens, buscando no sujeito aluno o despertar para a valorização do trabalho cartográfico participativo. O desafio cabe ao professor propor movimentos que envolvam todos os seus alunos.

Quando esses sujeitos, por serem agentes sociais, se mobilizam em ações cidadãs nas suas comunidades, o trabalho cartográfico proporciona construções de

Para0nde!?, Porto Alegre, v.15, n.1, p.01-15, 2021. http://seer.ufrgs.br/paraonde 
mapas mais significativos do espaço interativo. Nesse percurso, esses sujeitos podem desempenhar de forma compreensível um papel importante junto ao grupo participativo e representar a sua comunidade. Eles serão autores do mapeamento, em que através de uma identidade grupal, formada pela identidade proporcionada pelo trabalho em comum, cujo fim é estabelecer interação e comportamentos institucionalizados (BLEGER, 2011), podem mais facilmente exercer a cidadania.

Nesta linha, temos a importância de aprendermos a ler mapas. Para Souza e Katuta (2001, p. 76):

Ler mapas, como se fossem um texto escrito, ao contrário do que parece, não é uma atividade tão simples assim; para que isso ocorra, faz-se necessário aprender, além do alfabeto cartográfico, a leitura propriamente dita, entendida aqui não apenas como mera decodificação de símbolos. As noções, as habilidades e os conceitos de orientação e localização geográficas fazem parte de um conjunto de conhecimentos necessários, juntamente com muitos outros conceitos e informações, para que a leitura de mapas ocorra de forma que o aluno possa construir um entendimento geográfico da realidade.

Para ler mapas os alunos necessitam do entendimento das linguagens que os mapas trazem, que são códigos. Sem esta formação serão apenas copiadores. Em nosso entendimento, um bom leitor de mapas necessita ter clareza de como se processa a representação cartográfica.

Para nós a representação cartográfica envolve a organização de métodos como também de técnicas que são trabalhadas para representar por meio dos mapas as informações geográficas. Mas qual é o seu objetivo? Representar graficamente através da arte e da ciência as especificidades de determinado lugar. Desta forma, a informação cartográfica está ancorada na representação de um mapa base, que direciona a leitura, a representação, bem como, a interpretação das áreas mapeadas.

Seemann (2012, p. 13), alerta:

[...] O mapa, na verdade, não é um produto, mas um processo (mapeamento) que não se reduz a levantamentos topográficos e geodésicos, medidas de precisão e formas materiais, mas que pode ser igualmente espiritual, político ou moral e incluir o que é lembrado, imaginado e contemplado.

O autor aponta para o entendimento de que o mapa não apenas direciona para as questões planas do lugar, mas encaminha a pensar em uma relação social, portanto complexa. A leitura de mapas incorpora as novas formas de pensamento, no sentido de interpretar as relações comunicativas da realidade que se impõem ao espaço geográfico e não se fixando apenas no aspecto cartesiano dos mapas. A leitura de mapas exige um desprendimento lógico que vai além do tridimensional. Deve dar conta do multidimensional dinâmico.

Com um entendimento próximo, Roos e Ferraz (2017, p.3), corroboram ao escreverem: "[...] o mapa não se trata apenas de uma representação do mundo, mas ele também produz o mundo". A representação cartográfica auxilia o sujeito a dar sentido autoral aos fatores que podem ser abstraídos do mapa. 
Já a Cartografia Social provoca o sujeito a construir novos códigos que podem ser problematizados pelo professor e assim (re)avaliar em conjunto o seu emprego. Ela pode ser vista como um processo de construção coletiva. Não é um mapeamento imposto, mas é autoral e deve ser socializado na sua reflexão (ALMEIDA, 2010). É importante que o professor estabeleça aproximações, sempre que possível, as representações realizadas através da Cartografia Social com as representações Cartográficas.

Para nós a Cartografia Social é um caminho para a Cartografia, pois nos leva a entender a importância dos mapas e o aspecto da intensionalidade na elaboração de cada um. A Cartografia Social auxilia a reforçar as relações existentes em comunidades específicas e, portanto, de certa forma, a ler as paisagens próprias. Os mapas devem ser construídos com a participação dessas comunidades e usados como instrumento de compreensão, tensionamentos e defesa de seus direitos. Assim, o mapeamento participativo no ambiente escolar, estudando o espaço vivido através da representação das paisagens, direciona o sentido de extrair informações dos mapas construídos pelos próprios alunos.

Mas como fazer isso? Pelo protagonismo dos sujeitos envolvidos, pois, independente dos saberes da Cartografia, a Cartografia Social não se preocupa com a escala matemática correta, ela usa uma relação de razão e proporção, que potencializa a valorização do que é realçado pelo sujeito autor.

Os autores Neto e Costa (2016), colaboram pontuando que as relações do mundo contemporâneo devem ser compreendidas para além das quantificações. Seria este um dos objetivos da Cartografia Social, ou não? Acreditamos que sim, pois, a sua metodolologia é participativa. Após a sua representação, se estrutura numa concepção visível para os sujeitos. Por conseguinte, a Cartografia Social direciona o estudo do mapeamento participativo de determinado objeto, os símbolos e os aspectos culturais, que deverão fazer parte da legenda, são elencados a partir da existência dos alvos que fazem parte dos movimentos corriqueiros dos olhares nos seus espaços de (com)vivência.

Neste entendimento, o objeto a ser mapeado deve ser o espaço conhecido, isto é, o espaço cotidiano, cujos elementos são familiares. A decodificação dar-se-á com mais facilidade, quando no processo de alfabetização cartográfica, o aluno ao ser estimulado, codificou através de significados atribuídos às coisas da sua vivência e da sua imaginação o mapa de sua autoria.

\section{A cartografia social e a leitura da Paisagem}

"A paisagem é uma janela de possibilidades ilimitadas", assim escreveu Eric Dardel em 1990. E na Cartografia Social essa viabilidade parece abrir inúmeras janelas na representação cidadã, e esses estudos da Cartografia e da leitura das paisagens direcionam aos sujeitos práticas questionadoras em seu espaço de vivência. Para questionar é necessário ter entendimento e duvidar das verdades momentâneas. O professor deve refletir sobre a importância de desafiar os sujeitos a lerem o que não enxergam e enxergar o que está escondido no que é mostrado.

Para aprender a olhar a paisagem, saindo do cotidiano do ir e do vir, (que são movimentos de sentidos valorativos), é necessário trabalhar com a problematização do que se vê, principalmente o que está escondido no que observamos. 
Pensamos que nas aulas de Geografia o professor pode trabalhar a Cartografia construindo com aos seus alunos noções de orientação espacial, (saber orientar-se em relação aos objetos), localizar pontos no mapa através da coordenada, proporção através das escalas, mas sempre levando em consideração que a quantificação é meramente ocasional, pois o que importa na construção do mapa participativo são as relações com os elementos formadores do território. Leválos a construção da leitura de mapas, entendendo as simbologias, extrair informações para a interpretação espacial; ou seja, construir o conhecimento cartográfico buscando formar leitores conscientes para serem possíveis mapeadores. É como dizem Piaget e Inhelder (1993, p. 86), "a criança aprende agindo sobre o objeto, manipulando-o e descobrindo os elementos que 0 constituem".

\section{Passini (2012, p. 25), corrobora ao afirmar:}

Com a sistematização do processo de mapear, os elementos da realidade são ressignificados, e podemos afirmar que, nesse processo de mapear e ler o espaço de sua vivência, a criança desenvolveu as ferramentas da inteligência, como selecionar, classificar e relacionar realidade e significante.

Associado à construção deste conhecimento, o professor introduz novas possibilidades para a leitura da paisagem, pois "a paisagem não é somente uma vista; é também um território no qual interagimos", (PANIZZA, 2014, p. 22).

Como contribuições para este estudo, apontamos como importante, a formação de um pensamento crítico-reflexivo nas demandas de uma postura cidadã, no saber se posicionar frente à complexidade nas diferentes formas de paisagens. Isto porque, os movimentos da representação social, geram cenários familiares, que outrora eram desconhecidos, e através das imagens reproduzem estruturas conceituais de maneira visíveis. (MOSCOVICI , 2015).

Assim, entendemos que a Cartografia Social tem como princípio a auto representação do sujeito que se apropria da complexidade local e ali representa a sua identidade, ou seja, o seu lugar. Esse processo envolve percepção, concepção e representação. Por que é social? Por não se restringir a localizar e distribuir os elementos do espaço representado, mas sim expressar, por meio da representação, a teia de relações conflituosas que são tecidas processualmente e dão vida ao território.

Corroborando, com este pensamento, Santos (2016, p. 12) pontua que a "Cartografia Social envolve pesquisadores de diferentes formações e possui, como elemento fundamental, a participação dos agentes sociais no processo de feitura dos mapas".

Neste sentido, Gomes (2017, p. 11), pontua:

Uma consequência possível dessa CS é o engajamento da escola em demandas das pessoas do entorno, a emergência do protagonismo de crianças, jovens e seus familiares para reivindicações de melhorias para a própria escola, o bairro/ comunidade e, ou, cidade/campo. Além disso, pode emergir a valorização do território, dos seus saberes-fazeres, e, não raro, uma atitude positiva em relação ao lugar. O mapa situacional pode ser acompanhado de textos e fotografias, organizando um fascículo. Para isso, 
pode-se apoiar em diferentes tipos de materiais e formas, explorando a criatividade e a ludicidade.

Portanto, através da dialógica entre a Cartografia Escolar e a leitura da paisagem com o uso da Cartografia Social, podemos então propor algumas práticas no sentido do professor de Geografia tornar suas aulas não lineares.

Aulas lineares se baseiam na reincidência de aulas no dia a dia através da orientação de manuais pedagógicos em que o professor não procura também ser o autor. Há uma complexidade cada vez mais presente que precisa ser lida e, portanto, o professor necessita estar atento e buscando diferentes caminhos no movimento pedagógico.

Neste contexto, o professor linear, para tornar a aula não repetitiva, precisa entender que o ensino como construção de conhecimento deve rever em suas práticas o peso da reprodução, da memorização de dados isolados, sem questionamentos. Bem como, incluir o discente como sujeito de fala e escuta para novos diálogos no seu processo de ensinar e aprender. Professor sempre continua a aprender! Valorizar o saber contextualizar e o saber como dimensão do processo de ensino-aprendizagem, principalmente escutando e favorecendo a criatividade de cada sujeito aluno. E como diz Morin (2004, p.24), "O desenvolvimento da aptidão para contextualizar e globalizar os saberes torna-se um imperativo à educação". Como contextualizar e globalizar os saberes se não temos a linguagem do conhecimento? A questão da linguagem está relacionada ao raciocínio lógico, e, portanto do que entendemos por compreensão. Parece ser impossível compreendermos para explicar sem termos o conhecimento construído. São os conhecimentos adquiridos que nos possibilitam exercer a sabedoria. Para este movimento é fundamental que o professor busque diferentes caminhos metodológicos, muitos como desafios enfronhados numa pesquisa ação. É fundamental empregar diferentes linguagens e provocar diversas lógicas para o entendimento do conjunto indissociável do sistema de objetos e do sistema de ações que compreendem o Espaço Geográfico (CASTROGIOVANNI, 2011). Só assim estamos valorizando os movimentos metodológicos que cada vez mais se fazem presentes como opções de ensinar e aprender.

\section{Saindo do movimento de práticas lineares para práticas lúdicas interativas.}

Objetivando direcionar o nosso estudo para proposições que estamos chamando de não lineares, apresentamos movimentos que poderão apontar aos leitores opções de trabalho nos seus fazeres pedagógicos. Alertamos que a expressão "não lineares" não significa processos não planejados.

1. Considerando a relação local - global. Valorizando a Cartografia Social.

Atenção! A Cartografia Social pode estimular a construção dos conceitos de Região, Território, Espaço, Lugar, Paisagem, dando sentido à relação espaçonatureza-sociedade-espaço. Convém ao professor refletir teórica e epistemológicamente sobre as diversas possibilidades pedagógcas.

Com uma interpretação do que foi representado através da Cartografia Social é 
possivel discutir a totalidade do espaço. A relação global se faz presente na relação local, uma vez que munidos de exemplos do mundo, os sujeitos direcionam esses atributos para o seu espaço de vivência, comparando, questionando, levantando hipóteses e lançando exigências de alterações nas suas relações sociais. O espaço é uma totalidade, cada recorte espacial faz parte do todo, portanto, compõem e reflete o todo. A soma do estudo de cada parte é mais que o estudo da totalidade, assim auxilia a constituir a complexidade do Espaço Geográfico.

2. Valorizando os conhecimentos empíricos decorrentes das práticas cotidianas, em que os sujeitos produzem e interagem sobre elas, através de novas representações e percepções.

Panizza (2014, p. 46) nos fala que "aprender a observar, descrever, comparar, estabelecer, relações e correlações, tirar conclusões, fazer sínteses são habilidades necessárias para a vida cotidiana". E conclui: "através do exercício do olhar geográfico sobre a paisagem".

\section{Valorizando as práticas ao ar livre.}

Neste movimento pedagógico os alunos percorrem os seus locais de vivência. Com olhar geográfico problematizado poderão ver as marcas que fazem existir as paisagens, muitas delas antes não vistas.

O professor deve problematizar um tema relacionado à paisagem, assim estimular nos seus alunos um olhar intencional sobre ela, um olhar que busque elementos de análise, explicações e respostas, exercendo autoria (PANIZZA, 2014).

Diante destas orientações, é necessário provocarmos o olhar intencional, buscando as teorias construídas e que os alunos escrevam no diário de campo este novo olhar através de novos significados. Associado à escrita, o professor estimula o uso da fotografia, de fotos, imagens, depoimentos,que poderão ser utilizados em outros movimentos.

\section{Atividades e reflexões a partir da Cartografia Social com os aportes da BNCC.}

A Cartografia Social na sua desenvoltura, favorece mostrar as tonalidades do espaço de vivência, as identidades e as experiências dos sujeitos, e corrobora com a formação cidadã. Neste sentido a BNCC (2017), afirma que a utilização da linguagem cartográfica proporciona o desenvolvimento do raciocínio espaçotemporal, pois através da unidade temática "o sujeito e seu lugar no mundo" tem foco nas relações sociais.

As informações advindas da subjetividade dos sujeitos participantes, podem apresentar algumas divergências, ou mesmo algumas convergências, que devem ser tratadas. O espaço é tenso, é constituido por diferenças e pela diversidade nas formas de existir.

Em ação retroativa à exclusão social, buscam-se construções cidadãs. Pensamos que o conhecimento geográfico pode contribuir no sentido de mudanças no espaço escolar, se trabalharmos com a ideia de que existem diferentes caminhos de participação e de possibilidades de transformação.

Desta forma são esperadas possibilidades de decodificação das marcas da 
ação humana sobre o espaço existente, possibilitando novas leituras do lugar vivido e percebido, ou seja, de lugarização.

Milagres (2011, p.44), corrobora com este contexto:

[...] a cartografia social pode oferecer à comunidade uma melhor discussão a respeito do planejamento territorial, diferentemente da cartografia convencional que privilegia o caráter hierárquico e mais centralizador. A cartografia social como instrumento participativo é o próprio processo de elaborar mapa. [...] o mapa produzido pela cartografia social pode ser usado pela comunidade como centro de reflexão do território.

A Cartografia Social, apresenta movimentos participativos, com a interpretação dos fatores naturais e até sócioeconômicos, através de estudos e práticas de políticas públicas que direcionam para o despertar cidadão dos sujeitos envolvidos, na busca de novos pares no engajamento social construindo conteúdos.

Becker (2012, p. 36) nos fala:

Os conteúdos e os conceitos estruturantes são uma fonte inesgotável de elementos propulsionadores de situações nas quais o aluno pode agir e refletir, aprendendo através das ações que ele mesmo realiza e toma consciência de como as praticou.

Esta reflexão aponta que o trabalho participativo entre alunos sob a orientação do professor, gesta construções reflexivas, pois através de práticas exercidas por eles despertam consciência crítica através da realidade vivenciada. $O$ professor precisa ter clareza deste processo.

Por ser a Catografia Sistemática munida de movimentos lógicos-matemáticos na sua especificidade, a Cartografia Social é munida pela representação espontânea do sujeito, e numa provocação pelo estado da dúvida, pois, através da emoção, a representação do mapeador é emanada a partir de sua história envolvida com a cultura do local vivido - o seu lugar

É com este pensamento que cartografamos sugestões provisórias a serem refletidas como exemplos que podem ser trabalhadas. Neste sentido, o movimento pedagógico com mapas ou diagramas possibilitam construções reflexivas do espaço geográfico, a partir de técnicas e conceitos relativos ao mapa. A Cartografia Social é mais dinâmica, autoral e contemporânea ao desvendar o que a Geografia muitas vezes esconde e os mapas e diagramas não nos mostram. Em ambas, pensamos que o papel do professor é fundamental, pois é ele, com o seu conhecimento e a clareza epistêmica que provoca, desafia e auxilia na constituição das sínteses autorais.

Alertamos que essas atividades são sugestões que devem sofrer ação participativa dos professores e que são, primeiramente direcionadas aos alunos de Geografia do Ensino Fundamental. Os professores ao provocarem atividades como estas, por exemplo, estão auxiliando os alunos a entenderem que representar o espaço é um ato técnico, mas repleto de carga ideológica e de visões particulares de mundo inseridas no tempo e no espaço. Cada um de nós, pela nossa história, podemos representar diferentemente o mesmo espaço. 


\section{Atividades sugestivas}

1ำ Momento - Cartografia Social

\begin{tabular}{|l|l|}
\hline Tema & Reconhecer o espaço de vivência \\
\hline Objetivo & $\begin{array}{l}\text { Problematizar o cenário dos arredores da escola dando } \\
\text { sentido ao (des)conhecido }\end{array}$ \\
\hline $\begin{array}{l}\text { Habilidade } \\
\text { BNCC }\end{array}$ & $\begin{array}{l}\text { (EF03GE06) Identificar e interpretar imagens em diferentes } \\
\text { tipos de representações cartográficas }\end{array}$ \\
\hline Tema & \\
\hline Representações do espaço de (con)vivência - desenhando paisagens. \\
\hline Contextualização \\
\hline
\end{tabular}

Como é o meu lugar? Solicitar que os alunos façam um desenho de diferentes paisagens. Por exemplo, quarteirões entorno da escola, áreas de conflitos. No desenho considerar alguns elementos do espaço (enunciados), como: lugares que eu não posso ir perto da escola, lugares que eu gosto de ir perto da escola, pontos de encontro perto da escola, como é o entorno da escola, o que gostaria que tivesse em frente à escola, etc.

\section{PROBLEMATIZAÇÃO}

Quais destes lugares são facilmente vistos e quais não são vistos num primeiro momento? Por quê? Qual foi a paisagem que foi mais fácil ou mais difícil de ser desenhada? Por quê?

AÇÃO PROPOSITIVA

Realizar com a turma uma série de pontuações no quadro ou oralmente, de forma coletiva. Solicitar que voluntariamente cada aluna(o) expresse os seus desenhos, elencando os elementos de cada paisagem.

SISTEMATIZAÇÃO

Cada aluno, se assim desejar, apresenta ao grupo os seus desenhos e descreve-os.

SISTEMATIZAÇÃO FINAL

O professor faz uma síntese final, levantando novas questões e propondo, por exemplo, possibilidades de uma (re)ordenação de certos espaços mapeados e/ou trazidos como problema. Também devem ser valorizados os lugares como pontos de encontro e olhares sobre o que não é, geralmente visto. Pode desenvolver um projeto para melhorar espaço de convivência. 
2o Momento - Cartografia Sistemática

\begin{tabular}{|l|l|}
\hline Tema & Reconhecer o espaço de vivência \\
\hline Objetivo & $\begin{array}{l}\text { Problematizar o cenário dos arredores da escola dando } \\
\text { sentido ao (des)conhecido. }\end{array}$ \\
\hline $\begin{array}{c}\text { Habilidade } \\
\text { BNCC }\end{array}$ & $\begin{array}{l}\text { (EF03GE06) Identificar e interpretar imagens em diferentes } \\
\text { tipos de representações cartográficas. }\end{array}$ \\
\hline
\end{tabular}

Tema

Representações do espaço de (con)vivência - (re)desenhando paisagens.

PROBLEMATIZAÇÃO

Como é o meu lugar? O que eu não vejo no meu lugar?

AÇÃO PROPOSITIVA

a) - Realizar treinamentos com drone para dar suporte aos entendimentos das visões verticais, horizontais e oblíquas, no sentido de fotografar os lugares de vivência. Se não tiver drones conseguir imagens de diferentes ângulos de visão.

b) - Na escola, com os alunos, trabalhar o reconhecimento do lugar através da leitura das paisagens, onde serão indicadas as características do grupo envolvido. Para isto, fazer caminhadas com os alunos no entorno da escola e das moradias dos mesmos (ou na área limitada previamente pelo professor). De posse de câmara fotográfica ou celular, e do drone (se for possível), os alunos farão 0 registro fotográfico dos alvos que mais tenham representações para eles. Com as imagens obtidas, temos o conceito de visão, que se baseia na ideia de que representamos cartograficamente uma paisagem a partir de um ponto de vista, ou seja, do posicionamento de um observador em relação à paisagem representada. Aqui o uso do drone será muito relevante, mas não é decisivo. Essa prática é importante para o ato de construção do mapa participativo.

c) - Utilizar a carta topográfica do município e as imagens do Google Earth, para se apropriar da base cartográfica e, após a leitura, utilizar a técnica do overley, onde deverão ser desenhados elementos de interesse dos sujeitos, após o reconhecimento fotográfico de cada lugar - inserção nas paisagens.

\section{SISTEMATIZAÇÃO}

a) - Partindo das ações propositivas, a construção do mapeamento colaborativo, será construído pelos alunos, marcando no mapa do município, ou do bairro, ou da área delimitada, onde, preferencialmente esteja situada a escola (previamente entregue) a localização da escola, os pontos de riscos, 
sua moradia, posto de saúde, pontos de encontro, locais de concentração demográfica, locais de concentração de comércio, locais em que não podem frequentar, entre outros. Atenção! (os locais a serem marcados devem ser discutidos inicialmente com a turma) e fixando no mapa as fotografias das paisagens selecionadas pelos alunos. Procurar problematizar o percurso da casa de cada sujeito para a escola. Provocar a sua leitura através de descrições. Procurar depoimentos de moradores locais sobre o espaço a ser trabalhado.

b)- Neste contexto, ao se apropriar dos mapas construídos, com as informações em um só mapa, os alunos que são os próprios autores dos mapas participativos construirão um mapa visível para todos, e assim transformarão a informação em conhecimento.

c) Comparar as representações realizadas através da Cartografia Social com a Cartografia Sistemática e fazer discussões com os alunos valorizando as duas formas de representar o espaço geográfico. Levantar pontos objetivos e subjetivos em cada representação.

SISTEMATIZAÇÃO FINAL

- Para dar vistas ao trabalho, fazer debates sobre o uso das representações das diferentes paisagens, sob diversos olhares e apresentá-las à comunidade escolar e em reuniões nos centros urbanos, por exemplo. Outra possíbilidade, entre tantas, é possível construir uma produção com o título: Nosso Bairro é assim.

\section{Considerações provisórias}

Como professores, entendemos que é importante provocarmos diferentes movimentos para descobrirem o lugar da Geografia em nossas vidas. A Cartografia por sua vez possibilita práticas que são fortalecidas com os conceitos balizadores da Geografia. O conhecer teórico e epistemológico direciona a autonomia, pois professores com outra formação, ao ensinar Geografia, parece tolher o interesse do aluno pela componente curricular.

Esta contribuição foi tecida com os fios que direcionam articulações entre a Cartografia Social, Cartografia Sistemática e o conceito de Paisagem. Apresentamos caminhos e práticas de representação do espaço geográfico como possibilidades que embasam construções através da Cartografia Social, valorizando o despertar cidadão de cada sujeito numa forma de engajamento e encaminhamentos sociais e políticos junto à comunidade e, com isto, direcionamos para a valorização da Cartografia Sistemática na leitura e compreensão provisória das paisagens que compreendem os lugares.

Desta forma, por ser uma consideração provisória, questionamos: O professor que se apresenta linear, isto é, óbvio (SILVA, 2013), poderá trabalhar com a representação do espaço vivido pelos alunos, pois a representação social por si só é causadora de conhecimentos? Parece ser impossível. 
Pensamos que o professor no exercício do ensinar e aprender deva valorizar a escuta, o protagonismo de cada sujeito aluno, uma vez que a partir do envolvimento dos mesmos, há um despertar da sensibilidade no observar as paisagens, valorizar o olhar da dúvida, de desconfiança, de protagonismo na representação do seu lugar, aproximando-os às realidades locais, estabelecendo outras reflexões em escalas maiores e perceber que o espaço geográfico é uma totalidade.

Enquanto professores, precisamos trabalhar os conteúdos no sentido dos alunos não serem apenas receptores, mas protagonistas da compreensão das relações sociais, econômicas, ambientais, que ocorrem no seu espaço vivido, numa dialógica com o todo que é o espaço geográfico. O desafio está feito!

\section{Referências}

ALMEIDA, A. W. B. de. Cadernos de debates. Nova Cartografia Social: Conhecimentos Tradicionais na Pan-Amazônia. Manaus: PNCSA/UEA Edições. 2010.

BECKER, F. Educação e construção do conhecimento. Porto Alegre: Penso 2012. $199 \mathrm{pg}$.

BLEGER, J. Temas De Psicologia - Entrevista E Grupos - Col. Textos De Psicologia : Martins Fontes - 4⿳亠丷厂 Ed. 2011. 123 pg.

BRASIL. Ministério da Educação. Base Nacional Comum Curricular. Brasília: MEC, 2017

CASTROGIOVANNI, A. C. Espaço Geográfico Escola E Os Seus Arredores: descobertas e aprendizagens. IN: CALLAI, Helena (org.) Educação Geográfica: reflexão e prática. ljuí. Editora da Unijui. 2011. 320p

DARDEL, E. L'homme et la terre: nute de la réalité géographique. Paris: Presse Universitaires de France, 1990. v.1

GOMES, M de F. Vilas Boas. Cartografia Social e Geografia Escolar: aproximações e possibilidades. Revista Brasileira de Educação em Geografia. v. 7, n. 13, p. 97110, jan/jun, 2017.

GUARESCHI, P. Representações Sociais, Mídia e Movimentos Sociais. In: GUARESCHI P. (et al) (Org). Representações Sociais em Movimento: psicologia do ativismo político. Porto Alegre: EDIPURS, 2010. 77 - 91 pg.

MILAGRES, C. S. F. Uso da cartografia social e das técnicas participativas no ordenamento territorial em projetos de assentamento de reforma agrária. 2011. 153 pg. Dissertação (Mestrado) - Extensão Rural, Universidade Federal de Viçosa, 2011.

MORIN, E. A cabeça bem-feita: repensar a reforma, reformar o pensamento. 9. ed. Rio de Janeiro: Bertrand Brasil, 2004. 128 pg.

MOSCOVICI, S. Sobre Representações Sociais. (Traduzido por Clélia Nascimento Schulze para circulação interna). Núcleo de Psicologia Social, Departamento de Psicologia, UFSC, 2015. 408 pg.

NETO, V. P. B.; COSTA, M. da C. Saberes Docentes: entre concepções e categorizações. Revista tópicos Educacionais. v.22, n.2, 2016.

PANIZZA, A. de C. Paisagem. (Como eu Ensino). São Paulo: Editora 
Melhoramentos, 2014. $175 \mathrm{pg}$.

PASSINI, E. Y. Alfabetização cartográfica e a aprendizagem da Geografia. São Paulo: Cortez, 2012. 216 pg.

PIAGET, J.; INHELDER, Barbel. A representação do espaço na criança. Porto Alegre: Arte Médicas, 1993

ROSS, D.; FERRAZ, C. B. O. Categorias Geográficas: o que pode um mapa... Revista Geographia, v. 19, n. 41 , 2017. Pg. 88 a 96.

SANTOS, D. dos. CARTOGRAFIA SOCIAL : O estudo da cartografia social como perspectiva contemporânea da Geografia. Revista Geografia e Interdisciplinaridade. V. 2, n. 6 . p. 273-293, Maio-Agosto de 2016.

SANTOS, M. - Estrutura, Processo, Função e Forma como Categorias do Método Geográfico. In: Espaço e Método. São Paulo: Nobel, 1985. 120 pg.

SEEMANN, Jörn. Carto-Crônicas: uma viagem pelo mundo da cartografia. Gurupi (CE): Editora Veloso, 2012.

SILVA, P. R. F. de A e. Cartografando a construção do conhecimento cartográfico no ensino da Geografia. 2013. 252 pg. Tese Doutorado em Geografia. Programa de pós graduação em Geografia. Universidade Federal do Rio Grande do Sul. Rio Grande do Sul, 2013.

SOUZA, J. G.; KATUTA, A. Geografia e conhecimento cartográfico: A Cartografia no movimento de renovação da Geografia brasileira e a importância do uso de mapas. São Paulo: Editora da UNESP, 2001. 166 pg.

VIEIRA, L. de F. dos S. ; VERDUM, Roberto. A Estética da paisagem Cênica, Pitoresca, e Sublime. In: AZEVEDO, Ana Francisco; REGO, Nelson. (Orgs). Geografias e (In)visibilidades : Paisagens, Corpos, Memórias Porto Alegre: Compasso Lugar Cultura, 2017. 452 pg. 129 - 158 pg.

VERDUM, R.; VIEIRA, L. de F. dos S.; PIMENTEL, M. R. As Múltiplas Abordagens para o Estudo da Paisagem. Espaço Aberto, PPGG - UFRJ, v. 6, n.1, p. 131-150, 2016. 